\title{
Contribution of Italian spine research to peer reviewed publications
}

\author{
Claudio Lamartina $\cdot$ Giuseppe Banfi
}

Received: 24 February 2011/Published online: 10 March 2011

(C) Springer-Verlag 2011

In 2011, Italy celebrates 150 years of unification of the country, when various kingdoms and states became a Nation. There are still many differences among regions of Italy, despite a long-lasting political and economical commitment in homogenizing the social discrepancies and assuring common standards and rules for all the citizens and for all the territories. The coming of the European Community was more important than the national profile, but, paradoxically, the creation of a great Europe developed the requests and hopes of smaller entities, in Italy but also in other countries. Differences among regions are plain also in health and social services. In Italy, a Servizio Sanitario Nazionale (National Health Service) was built 30 years ago, but regional health services, born from the new federal evolution of state organization, could have some discrepancies. However, the Servizio Sanitario Nazionale was internationally known and renowned and it is one of the best in the world. This result was mainly derived from the high scientific level and professional engagement of Italian doctors, supported by universities and medical and scientific associations. The quality of care is directly linked to basic and applied research. The research centers in Italy are not only academic, industrial or independent from healthcare services, but are also organized in a network coordinated by the Ministry of Health, which controls and supports the Scientific Institutes of Research and Care (Istituti di Ricerca e Cura a Carattere Scientifico-IRCCS), i.e., public and private hospitals, which have common and parallel missions: care and science. This model is now

C. Lamartina $(\bowtie) \cdot$ G. Banfi

II Spine Surgery Department, IRCCS Istituto Ortopedico

Galeazzi, Via Riccardo Galeazzi, 4, 20126 Milan, Italy

e-mail: c.lamartina@chirurgiavertebrale.net widely appreciated in the world and represents a concrete example of a real investment and commitment in translational research, in collaboration with industries, governments, non-profit organizations and patients' associations. The high basic level of medicine should always be accompanied by excellence and reference centers, especially for special surgery. It is particularly noted for spine surgery. We outline the engagement and effort of Italian spine surgeons in improving scientific activities, surgery techniques, ward organization, hospitalization, diagnostic services integration, but also research and teaching. In fact, in 2011 the annual meeting of the Spine Society of Europe will be held in Italy. Every year, the National Congress of the Italian Spine Society-GIS collects many hundreds of participants, every month educational programmes of international and national associations are organized in different cities. This issue aims to stimulate Italian spine surgeons to be represented in the international spinal literature in a way that better reflects the scientific level achieved by them and their national medical organization.

We reviewed the articles which appeared in the journals devoted to spine surgery included in Journal Citation Report (JCR), namely Spine, European Spine Journal and Journal of Spinal Disorders and Techniques, comparing the Italian contribution to the total knowledge represented by published papers (Table 1). It is obviously a rough evaluation, because contributions from engineering, biomechanics, and general orthopaedics journals should be added, but it is sufficient to define a rising and stable contribution from Italy to the spine surgery science, considering that the national level is between the 5th and 8th rank in the observed years.

Our aim is to stimulate and to improve the Italian contribution to peer-reviewed international journals. This Supplement including a selection of the oral presentations 
Table 1 Values of impact factor scores of the three specialized spine journal quoted in JCR: the partial impact factor values are the value obtained by Italian professionals

\begin{tabular}{lccc}
\hline & Year 2008 & Year 2009 & Year 2010 \\
\hline Total impact factor & $2,409.9$ & $2,665.7$ & $2,688.2$ \\
Partial impact factor & 70.3 & 109.2 & 62.6 \\
\hline
\end{tabular}

The values of impact factors are derived from JCR. The contribution to total impact factor is different for the three journals: Spine in 2010 represents $70 \%$, European Spine Journal $25 \%$ and the Journal of Spinal Disorders and Techniques 5\% (data of 2010)

of the National Congress of the Italian Spine Society-GIS held in Ragusa in 2009, is a seminal part of this effort.
Giuseppe Banfi, MD

Scientific Director

IRCCS Istituto Ortopedico Galeazzi

Claudio Lamartina, MD

Chief of II Spine Surgery Dept.

IRCCS Istituto Ortopedico Galeazzi

Conflict of interest None. 